\title{
Em questões de gênero e normativi- dade, quantos passos avançamos no salão?
}

\author{
In terms of gender and normativity, how many \\ steps do we take in the ballroom? \\ En términos de género y normatividad, \\ ¿cuántos pasos damos en los salóns?
}

Francisca Jocélia de Oliveira Freire Universidade Federal da Bahia E-mail: joceliafreiredancadesalao@gmail.com ORCID: https://orcid.org/0000-0003-1891-5025

Cecília Bastos da Costa Accioly

Universidade Federal da Bahia

E-mail: ceciliaccioly@ufba.br ORCID: https://orcid.org/0000-0002-9024-8258

RESUMO:

Este artigo tem como questão principal a relação entre aulas de Danças de Salão, machismo e heteronormatividade. Coloca-se em pauta as seguintes perguntas: aulas de Danças de Salão estabelecem que tipo de relação com as questões de gênero e normatividade atualmente? São espaços de manutenção ou superação do machismo e da heteronormatividade? Apresenta-se aspectos encontrados durante a análise de dados coletados através de questionários relacionados à pesquisa em andamento, discutindo sobre concepções pedagógicas para as Danças de Salão; machismo; estudos de gênero; interseccionalidade; sexualidade e educação.

Palavras-chave: Danças de Salão. Estudos de Gênero. Heteronormatividade. Machismo.

FREIRE, Francisca Jocélia de Oliveira; ACCIOLY, Cecília Bastos da Costa. Em questões de gênero e normatividade, quantos passos avançamos no salão?.

PÓS:Revista do Programa de Pós-graduação em Artes da EBA/UFMG. v. 11, n. 22, mai-ago. 2021 Disponível em < $\underline{\text { https://doi.org/10.35699/2237-5864.2021.25827 }>}$ 


\section{ABSTRACT:}

The main issue of this article is the relationship between ballroom dancing classes, sexism and heteronormativity. It raises the following questions: what kind of discussion with gender and normativity issues today do ballroom dancing classes establish? Are these spaces for maintaining or overcoming sexism and heteronormativity? It presents aspects found during the analysis of data collected through questionnaires related to ongoing research, discussing pedagogical concepts for Ballroom Dances; sexism; gender studies; intersectionality; sexuality and education.

Keywords: Ballroom Dances. Gender Studies. Heteronormativity. Sexism.

\section{RESUMEN:}

El tema principal de este artículo es la relación entre clases de bailes de salón, machismo y heteronormatividad. Plantea las siguientes preguntas: ¿Las clases de bailes de salón establecen qué tipo de relación con los temas de género y normatividad en la actualidad? ¿Son espacios para mantener o superar el machismo y la heteronormatividad? Presenta aspectos encontrados durante el análisis de datos recolectados a través de cuestionarios relacionados con la investigación en curso, discutiendo conceptos pedagógicos para Bailes de Salón; machismo; estudios de género; interseccionalidad; sexualidad y educación.

Palabras clave: Bailes de salón. Estudios de Género. Heteronormatividad. Machismo.

Artigo recebido em: 15/10/2020

Artigo aprovado em: 06/04/2021

FREIRE, Francisca Jocélia de Oliveira; ACCIOLY, Cecília Bastos da Costa. Em questóes de gênero e normatividade, quantos passos avançamos no salão?.

PÓS:Revista do Programa de Pós-graduação em Artes da EBA/UFMG. v. 11, n. 22, mai-ago. 2021

Disponível em < https://doi.org/10.35699/2237-5864.2021.25827> 


\section{Introdução}

As questões que ganham força na atualidade como machismo, sexismo, papéis da mulher na sociedade, heteronormatividade, gênero e relações de poder perpassam as Danças de Salão, posto que nascem em uma sociedade patriarcal e machista, e as perspectivas produzidas por essa sociedade têm sido reafirmadas dentro de suas técnicas. Ao longo do tempo, agentes atuantes nas Danças de Salão continuam a reproduzir tais papéis que determinam como a mulher e como o homem devem se portar. Diante da realidade mencionada, consideramos que um dos lugares que apresentam um grande potencial para reafirmar e reproduzir concepções machistas e heteronormativas é a sala de aula e a ação pedagógica de profissionais que ensinam Danças de Salão.

Nesta acepção, torna-se fundamental compreender as metodologias e as ações pedagógicas que são utilizadas por profissionais para construção das aulas e que estão presentes na maioria das escolas, espaços e academias que promovem o ensino de Danças de Salão, reconhecendo as características que são comuns e servem como mecanismo de manutenção de uma aula com aspectos tradicionais, não somente acerca da técnica, mas no que diz respeito à propagação de pensamentos machistas e heteronormativos.

O presente trabalho aborda alguns dos principais aspectos da pesquisa desenvolvida entre os anos de 2019 e 2020, que teve como objetivo realizar uma análise crítica acerca do atual formato das aulas de Danças de Salão e sua constituição, apontando para possíveis ações pedagógicas que fomentem e difundam as Danças de Salão a partir de bases teóricas que questionem seus atuais formatos. Para tanto, compreendemos a necessidade de identificar os aspectos presentes nas aulas de Danças de Salão que funcionam como mecanismos para manutenção do seu formato tradicional machista e heteronormativo. Esta pesquisa é um convite para repensarmos tal formato, acessando estudos que abordam as Danças de Salão por perspectivas contemporâneas, feministas, racializadas e interseccionais.

FREIRE, Francisca Jocélia de Oliveira; ACCIOLY, Cecília Bastos da Costa. Em questões de gênero e normatividade, quantos passos avançamos no salão?.

PÓS:Revista do Programa de Pós-graduação em Artes da EBA/UFMG. v. 11, n. 22, mai-ago. 2021 Disponível em < https://doi.org/10.35699/2237-5864.2021.25827> 


\section{Metodologia}

Referente à metodologia, esta pesquisa se caracteriza como qualitativa, especificamente como pesquisa-ação, que objetiva prioritariamente, de acordo com Nunes e Infante (1996, p. 100), "equacionar os problemas por meio do levantamento de soluções e propostas de ações para transformação da realidade. O resultado do trabalho é proveniente da troca de saberes entre pesquisadores e profissionais da organização". Faz-se necessário afirmar ainda a intenção da transformação de nossa própria prática docente em dança.

Desta forma, iniciamos com um levantamento teórico que ajudou no entendimento dos conceitos utilizados.

Nos aspectos pedagógicos, a partir de d'Ávila e Madeira (2018), encontramos suporte para analisar as questões que envolvem o fazer pedagógico, os elementos que constituem a ação e a formação do professor, colaborando para reconhecer os limites percebidos nos profissionais que estão atuando como professores e instrutores de Danças de Salão.

Com Feitoza (2011), Polezi e Vasconcelos (2017), Pazetto e Samways (2018), Nunes e Froehlich (2018), pudemos dialogar diretamente com as questões apontadas na pesquisa, pois colocam em pauta os formatos tradicionais das Danças de Salão, principalmente no que diz respeito aos papéis construídos de acordo com prerrogativas de gênero. Além disso, tratam de aspectos referentes à condução e às relações de poder impostas através dela, pontos que consideramos cruciais para um olhar crítico sobre os formatos tradicionais em que as Danças de Salão foram construídas e ainda se mantêm. Os estudos acerca da condução propõem um olhar para um elemento muito tratado nas Danças de Salão, com destaque para a pesquisa realizada por Feitoza (2011), que aborda questões atreladas à condução nas Danças de Salão, sugerindo estudos acerca do entendimento de "Cocondução" em sua dissertação de mestrado. Essas são produções teóricas fundamentais para o desenvolvimento do trabalho e seu embasamento, colaborando também para acessar profissionais que estão propondo diferentes abordagens acerca das Danças de Salão, contribuindo efetivamente para desconstrução de estereótipos construídos por uma sociedade machista e heteronormativa.

FREIRE, Francisca Jocélia de Oliveira; ACCIOLY, Cecília Bastos da Costa. Em questões de gênero e normatividade, quantos passos avançamos no salão?.

PÓS:Revista do Programa de Pós-graduação em Artes da EBA/UFMG. v. 11, n. 22, mai-ago. 2021

Disponível em < https://doi.org/10.35699/2237-5864.2021.25827> 
Para compreender o conceito de machismo, utilizamos Drumont (1980). Sobre estudos de gênero e sexualidade, encontramos em Saffioti (2015) e Louro (1997) o processo histórico que colabora para estabelecer essas noções a partir do feminismo. Essas autoras fazem emergir alguns pontos que trazemos para as Danças de Salão, contribuindo para o entendimento do papel da mulher nesse lugar. A afirmação de Louro, indicando que "a segregação social e política a que as mulheres foram historicamente conduzidas tivera como consequência a sua ampla invisibilidade como sujeito" (1997, p. 17), pode ser diretamente relacionada às práticas das Danças de Salão que estabelecem para as mulheres determinados papéis que reforçam essa invisibilidade. Esta abordagem é indissociável do que aponta Akotirene (2019) quando discute a interseccionalidade, uma categoria teórica que possibilita uma análise múltipla de sistemas de opressão, entre eles a construção do poder estabelecido socialmente no sistema cis-hétero-patriarcal que, em nossa compreensão, é o mesmo que serve como modelo para as determinações estabelecidas no formato tradicional das Danças de Salão.

Em seguida, foram elaborados 3 questionários e aplicados utilizando programa de criação de formulários online gratuito. Estes foram validados através da realização de pilotos, e cada participante respondeu aos questionários após indicar estar de acordo com o informado no Termo de Consentimento Livre e Esclarecido. Tais questionários, aplicados como método para levantamento de dados para pesquisa, foram enviados por meio de e-mail e aplicativo gratuito para mensagens nos seguintes períodos: Questionários 1 e 2 entre 27 de outubro de 2019 e 3 de novembro 2019; e Questionário 3 entre 28 de março de 2020 e 10 de abril de 2020. O Questionário 1 foi enviado para 55 profissionais atuantes como professores e instrutores de Danças de Salão nas cidades de Salvador e Feira de Santana, Bahia; o Questionário 2 foi enviado para professoras, instrutoras e profissionais das Danças de Salão autoidentificadas como mulheres (cis e trans) em resposta ao Questionário 1 atuantes nas cidades mencionadas; e o Questionário 3 foi direcionado para estudantes, alunes, praticantes amadores e frequentadores de bailes e aulas de Danças de Salão na cidade de Salvador, Bahia. Os dados foram analisados em planilhas e gráficos, em sistema gratuito de armazenamento em nuvem.

FREIRE, Francisca Jocélia de Oliveira; ACCIOLY, Cecília Bastos da Costa. Em questões de gênero e normatividade, quantos passos avançamos no salão?.

PÓS:Revista do Programa de Pós-graduação em Artes da EBA/UFMG. v. 11, n. 22, mai-ago. 2021 Disponível em < $\underline{\text { https://doi.org/10.35699/2237-5864.2021.25827 }>~}$ 
A aplicação do Questionário 1 teve o intuito de identificar a formação profissional, as concepções pedagógicas, o planejamento das aulas, se as questões levantadas nesta pesquisa são abordadas durante a prática docente, quais as nomenclaturas utilizadas e se nas aulas existem papéis determinados para homens e para mulheres.

Na análise do Questionário 1, foi verificado que há uma diferença entre ser professor/instrutor identificado como homem e ser professora/instrutora identificada como mulher, percebida a partir do cotidiano profissional e referenciada nas análises teóricas. Como afirma Zamoner (2011 apud NUNES; FROEHLICH, p. 3), "atualmente, a dança de salão ainda é entendida como uma estrutura dual, em que o masculino é representado pelo cavalheiro que conduz; e o feminino, pela dama que responde", o que, consequentemente, provoca experiências distintas para diferentes gêneros nos ambientes de Danças de Salão. Ou seja, "essa maneira de estruturação é reflexo dos papéis sociais exercidos por homens e mulheres na época do surgimento da dança de salão" (ZAMONER, 2011 apud NUNES; FROEHLICH, p. 3) e tais papéis são carregados de significados construídos a partir de concepções machistas, sexistas e heteronormativas resultantes de uma sociedade patriarcal "que, como o próprio nome indica, é o regime da dominação-exploração das mulheres pelos homens" (SAFFIOTI, 2015, p. 44). Com essa indicação, a partir do Questionário 1, foi aplicado um segundo questionário (Questionário 2) para compreensão das experiências vivenciadas por pessoas autoidentificadas como mulheres (cis e trans) em exercício docente em sala de aula de Danças de Salão.

A aplicação do Questionário 3 teve o intuito de identificar o que o público frequentador dos espaços de Danças de Salão percebe em aulas e/ou práticas dançantes, suas concepções acerca dessas danças, se as questões levantadas nesta pesquisa são abordadas durante as aulas e sua visão sobre o assunto, quais as nomenclaturas utilizadas, e se nas aulas ou espaços frequentados existem papéis determinados para homens e para mulheres. Além disso, aplicar um questionário específico para estudantes, alunes, praticantes amadores, frequentadores de bailes e aulas de Danças de Salão amplia nossas informações sobre os ambientes onde as Danças de Salão acontecem, nos permitindo acompanhar o olhar profissional para/sobre essas danças e o olhar de praticantes amadores e em processos educacionais.

FREIRE, Francisca Jocélia de Oliveira; ACCIOLY, Cecília Bastos da Costa. Em questões de gênero e normatividade, quantos passos avançamos no salão?.

PÓS:Revista do Programa de Pós-graduação em Artes da EBA/UFMG. v. 11, n. 22, mai-ago. 2021 Disponível em < $\underline{\text { https://doi.org/10.35699/2237-5864.2021.25827 }>~}$ 


\section{Análise de dados}

O Questionário 1 foi enviado para 55 profissionais e tivemos respostas de 28 deles, com idades entre 24 e 63 anos. Nos quesitos: "sexo designado no nascimento" tivemos $15(53,6 \%)$ respondentes indicando "masculino" e 13 (46,4\%) "feminino"; "identidade de gênero" 14 pessoas identificaram-se como "homens-cis" (50\%), 13 como "mulheres-cis" (46,4\%) e 1 (3,6\%) "não binário"; "orientação sexual" tivemos $25(89,3 \%)$ participantes que se declararam "heterossexuais" e $3(10,7 \%)$ participantes se declararam "homossexuais".

O Questionário 2 foi enviado para ser respondido apenas por profissionais que se identificaram como mulheres (cis e trans) no questionário anterior. Das 15 respostas que recebemos, apenas 11 foram de fato elaboradas por mulheres anteriormente identificadas no Questionário 1 e as 4 outras foram elaboradas por homens identificados como tal no primeiro questionário. Gostaríamos de salientar que todas as perguntas feitas no Questionário 2 foram direcionadas para as referidas mulheres.

O Questionário 3 foi enviado para diversos grupos e muitos participantes solicitaram o envio para outros grupos particulares de turmas específicas de Danças de Salão, totalizando 250 pessoas. Tivemos respostas de 66 dessas, com idades entre 20 e 76 anos. Nos quesitos: "sexo designado no nascimento" tivemos 15 (22,7\%) respostas indicando "masculino" e 51 (77,3\%) "feminino"; "identidade de gênero" responderam 11 "homens-cis" (16,7\%), 51 "mulheres-cis" (77,3\%) e 2 (3\%) "não binário", 2 (3,0\%) pessoas escolheram o item "outros", descrevendo nominalmente 1 "heterossexual" e 1 "homem"; "orientação sexual" apresentaram-se 62 (93,9\%) "heterossexuais", 1 (1,5\%) "homossexual" e 3 (4,5\%) "bissexuais".

Podemos observar, a partir dos dados obtidos, que ainda se trata de um espaço predominantemente heterossexual, o que colabora para a reprodução de perspectivas heteronormativas sobre as Danças de Salão que, consequentemente, reproduzem uma lógica de comportamento baseada na binaridade de gênero e na manutenção de comportamentos estabelecidos para homens e mulheres. Como afirmam Pazetto e Samways (2018, p. 169):

FREIRE, Francisca Jocélia de Oliveira; ACCIOLY, Cecília Bastos da Costa. Em questões de gênero e normatividade, quantos passos avançamos no salão?

PÓS:Revista do Programa de Pós-graduação em Artes da EBA/UFMG. v. 11, n. 22, mai-ago. 2021

Disponível em < $\underline{\text { https://doi.org/10.35699/2237-5864.2021.25827 }>~}$ 
fica evidente a atuação da dança na conformação da ideologia heterossexual e sexista, que se sustenta na afirmação de que homens e mulheres são diferentes - e complementares - não apenas em relação a características corporais, mas em relação a características psíquicas, racionais, comportamentais, gestuais, sendo que essa suposta diferença é usada para justificar posições socioculturais atribuídas a homens e mulheres.

Percebemos, através das respostas, que o significado de identidade de gênero ainda não é entendido por muitos dos profissionais atuantes no ensino de Danças de Salão, o que interfere na sua compreensão da importância de tal assunto para preparação de aulas, para atuação profissional e produção de eventos. Isso fica nítido quando 21 dos 28 participantes respondem que as questões de gênero não interferem no seu planejamento.

Aqui, é fundamental compreender que, apesar de "cada feminista enfatiza[r] determinado aspecto do gênero, havendo um campo, ainda que limitado, de consenso[,] o gênero é a construção social do masculino e do feminino" (SAFFIOTI, 2015, p. 45). É necessário o entendimento de que gênero é algo construído socialmente e, desta forma, passível de mudanças. Perceber essa categoria como algo que pode ter seu significado modificado é indispensável para tratar de papéis pré-determinados nas Danças de Salão e discutir as implicações do que representa a continuidade do uso de nomenclaturas como "damas" e "cavalheiros".

Apesar de participantes se identificarem como profissionais atuantes no ensino de Danças de Salão, a maioria não buscou formação especializada na área. Assim, é restrito o número de profissionais com graduação em Licenciatura em Dança ministrando aulas de Danças de Salão (do total de respondentes, 4 pessoas declararam formação em Dança no Ensino Superior), mesmo que 100\% dos participantes estejam atuando em salas de aula. Alguns profissionais não compreendem como relacionar bases teóricas na preparação de suas aulas e outros nem sabem o que vêm a ser bases teóricas. Nesse aspecto, como afirmam d'Ávila e Madeira (2018, p. 21) “muitos professores ensinam sem o devido conhecimento dos saberes que sustentam sua própria prática - saberes pedagógicodidáticos", o que pode colaborar para uma abordagem tecnicista de reprodução de práticas, sem criticidade.

FREIRE, Francisca Jocélia de Oliveira; ACCIOLY, Cecília Bastos da Costa. Em questóes de gênero e normatividade, quantos passos avançamos no salão?.

PÓS:Revista do Programa de Pós-graduação em Artes da EBA/UFMG. v. 11, n. 22, mai-ago. 2021 Disponível em < https://doi.org/10.35699/2237-5864.2021.25827> 
Sobre machismo, mesmo com $89,3 \%$ do total de participantes declarando que se preocupam com discursos machistas em suas aulas, são muitos os relatos que ressaltam o papel de condutores para homens e o papel de conduzidas para mulheres. Além disso, no que diz respeito à determinação de funções em sala de aula por gênero, 64\% declaram que não há, o que diverge das respostas para questões abertas, que indicam diferenciações marcadas por designações sociais normativas de gênero (homem/mulher-cis).

Ao enviar os questionários, foi explicado que o Questionário 2 deveria ser respondido apenas por pessoas que se identificaram no Questionário 1 como mulheres. No entanto, 4 homens o responderam deliberadamente, mesmo com todas as perguntas direcionadas para estas mulheres. Isso é um dado que reflete uma situação que vai além do explícito nas respostas diretamente indicadas no questionário e acontece com frequência em aulas, eventos e cursos, onde costumeiramente o homem toma a iniciativa de responder às questões colocadas por praticantes, reafirmando o papel secundário da professora/instrutora mulher em ação, o que demonstra o quanto estamos impregnados do discurso-prática do patriarcado, esse "sistema político modelador da cultura e dominação masculina, especialmente contra as mulheres" (AKOTIRENE, 2019, p. 118).

Como já informado, 11 mulheres responderam ao Questionário 2 e tivemos o mesmo número de pessoas relatando que trabalham em parceria com homens. A maioria (54\%) considera importante a participação de outro indivíduo na aula - vale salientar que as mesmas não consideram necessário que sua parceria seja feita com um homem.

Tratando de ações machistas em sala de aula, grande parte relata que nunca vivenciou nenhum preconceito por ser mulher ao ministrar aulas de Danças de Salão, ou seja, parceiros e pessoas com quem realizam as aulas não apresentam atitudes machistas e heteronormativas (86\%), o que diverge das respostas das questões abertas, que indicam silenciamentos, descrédito, desconfiança sobre a capacidade, papéis determinados por concepções patriarcais.

Quando se trata da ação da mulher como professora em sala de aula e quem direciona tais ações, consideramos que a porcentagem apresentada ainda é pequena em relação ao total, pois 53,3\% dividem a atuação em sala, sendo que $13,3 \%$ indicaram seus parceiros como protagonistas. No

FREIRE, Francisca Jocélia de Oliveira; ACCIOLY, Cecília Bastos da Costa. Em questões de gênero e normatividade, quantos passos avançamos no salão?.

PÓS:Revista do Programa de Pós-graduação em Artes da EBA/UFMG. v. 11, n. 22, mai-ago. 2021

Disponível em < $\underline{\text { https://doi.org/10.35699/2237-5864.2021.25827 }>~}$ 
entanto, pelas experiências que constantemente atravessam o cotidiano profissional das Danças de Salão, é possível perceber que a maioria dos protagonistas em salas de aula ainda são os homenscis.

Ao abordarmos aspectos sobre o protagonismo no planejamento de ensino em aulas realizadas em parceria, analisando as respostas recebidas verificamos que muitas participantes não entendem o que é o planejamento de aula, além de nos depararmos com respostas dadas pelos homens no Questionário 1 como: "Total por conta da experiência. Porém sempre aberto a sugestão da parceira ou da equipe" e "Sou o mentor da criação". Essas frases carregadas de poder sobre a ação demonstram o quão machistas são as relações estabelecidas entre algumas parcerias, compreendendo que o "machismo é definido como um sistema de representações simbólicas, que mistifica as relações de exploração, de dominação, de sujeição entre o homem e a mulher" (DRUMONT, 1980, p. 1).

Referente ao Questionário 3, as respostas que obtivemos demonstram o quanto as aulas de Danças de Salão ainda são espaços frequentados predominantemente por mulheres, pois, dos 66 respondentes, 51 se declaram do sexo feminino $(77,3 \%)$ e, dessas, todas se declaram como mulheres-cis. No total das respostas podemos identificar um público que ainda é majoritariamente heterossexual (93,9\%), o que colabora para a afirmação de um espaço também heteronormativo. Como um espaço de práticas pautadas em concepções tradicionais, "a heteronormatividade na dança de salão funciona como engrenagem de um mecanismo social que regula corpos e possibilidades de estar no mundo" (SILVEIRA, 2018, p. 6), determinando funções e comportamentos preestabelecidos para homens e mulheres.

Podemos destacar as aulas em grupo $(84,8 \%)$ e os bailes $(60,6 \%)$ como os espaços utilizados pela maior parte das pessoas como acesso às Danças de Salão, o que afirma a importância da ação docente. De acordo com esses participantes, as duplas de profissionais atuando em salas de aula, em sua maioria, ainda são compostas por um professor e uma professora (54,5\%), e a figura do professor homem é apontada por 31,8\% das pessoas praticantes como quem ministra as aulas, o que indica que, apesar de serem espaços frequentados por um número maior de mulheres, ainda são espaços que apresentam homens na condução das atividades. No entanto, mesmo quando existe uma professora e um professor em sala de aula, “o papel da dama na dança está diretamente conectado com uma conduta moral vinculada a uma norma heterossocial, onde a centralidade e o

FREIRE, Francisca Jocélia de Oliveira; ACCIOLY, Cecília Bastos da Costa. Em questões de gênero e normatividade, quantos passos avançamos no salão?.

PÓS:Revista do Programa de Pós-graduação em Artes da EBA/UFMG. v. 11, n. 22, mai-ago. 2021

Disponível em < $\underline{\text { https://doi.org/10.35699/2237-5864.2021.25827 }>~}$ 
pensar concentram-se na figura masculina" (SILVEIRA, 2018, p. 8), por isso se reproduz um entendimento que "tudo que não se enquadre nesse gênero é visto como algo dissidente e inferiorizado" (SILVEIRA, 2018, p. 8). Assim, as professoras, em muitas situações, são vistas como assistentes, e em alguns casos seus nomes não são mencionados.

A maioria das pessoas declaram que o gênero de quem ministra a aula não interfere na atuação profissional e $74,2 \%$ declaram que as questões de gênero são abordadas em salas de aula. Ao relatar como isso acontece durante as aulas, no entanto, as respostas dadas às questões abertas, discursivas, estão diretamente atreladas à questão do respeito e cuidado com o outro, o que não necessariamente tem relação com as questões de gênero. $O$ que as respostas demonstram é uma inexistência do entendimento do que seria uma real abordagem sobre essas questões em sala de aula.

Dos participantes, 63,6\% afirmam preocupação com colocações machistas e sexualizadas nas aulas. Porém, continuamos a reproduzir uma dança na qual "um dos poucos espaços onde a dama tem a possibilidade de demonstrar sua criatividade e autonomia é através dos movimentos chamados de enfeites" (SILVEIRA, 2018, p. 12), considerando ainda a existência de uma condição para tal "criatividade e autonomia" serem utilizadas durante a dança, pois tais "gestos só podem acontecer se ela estiver atenta para não atrapalhar o movimento do cavalheiro que está por vir" (SILVEIRA, 2018, p. 12).

A nomenclatura condutoras/condutores e conduzidas/conduzidos está sendo mais frequentemente utilizada nas aulas, porém é perceptível no cotidiano profissional que essa realidade é resultado da compreensão do uso dessas palavras como criação de um modismo acrítico sem que esses profissionais de fato busquem engajamento nas ações políticas que trazem, na mudança de nomenclaturas, atitudes que colaboram para a superação do machismo e da heteronormatividade. Podemos perceber, nas respostas abertas dos questionários aplicados, uma normalização de determinadas condutas, referendadas por afirmações como "O homem no papel de condutor e mulher de conduzida" (resposta dada por um profissional), já que estamos falando de um espaço prioritariamente heteronormativo, influenciado pela visão patriarcal de sociedade, consequentemente, machista. Quando profissionais mudam as nomenclaturas utilizadas em sala sem nenhuma relação com mudanças de concepções e atitudes, utilizando indicações como "Os Condutores" e "As Condu-

FREIRE, Francisca Jocélia de Oliveira; ACCIOLY, Cecília Bastos da Costa. Em questões de gênero e normatividade, quantos passos avançamos no salão?.

PÓS:Revista do Programa de Pós-graduação em Artes da EBA/UFMG. v. 11, n. 22, mai-ago. 2021 Disponível em < $\underline{\text { https://doi.org/10.35699/2237-5864.2021.25827 }>~}$ 
zidas", mantêm a generificação dos papéis, ou seja, homens continuam a conduzir e mulheres a ser conduzidas, ressaltando que "o termo conduzir nas danças de salão tem sido entendido como uma ação na qual um corpo tem o domínio sobre outro no acontecimento da dança" (FEITOZA, 2011, p. 9), o que reafirma o poder de decisão e de controle da Dança exclusivamente aos homens, pensando a condução por uma visão tradicionalista.

Apesar da maioria (62\%) responder que não existem funções predeterminadas em sala de aula para homens e mulheres, $69 \%$ também declaram ter presenciado atitudes machistas nos espaços de Danças de Salão e alguns relatam que existe um olhar preconceituoso para pessoas do mesmo gênero dançando juntas. As colocações feitas durante a pesquisa, em afirmações como "Mulher movimentos de braços e dançar com salto" (resposta de um professor homem-cis) e "Dentro da dança de salão temos papéis definidos [...] Acredito que deve-se respeitar o papel de cavalheiro como o condutor [...] É preciso entender que são papéis dentro da dança [...]" (resposta de uma aluna mulher-cis), confirmam a manutenção de comportamentos e atitudes, nos espaços de dança, que ainda seguem padrões tradicionais e estão mergulhados em valores carregados de machismo, sexismo, heteronormatividade, atrelando funções corporais a papéis construídos socialmente. Aulas e ações pedagógicas continuam a reproduzir padrões sociais acerca do que é ser homem e o que é ser mulher, como indicam Nunes e Froehlich (2018, p. 95): "historicamente, nas Danças de Salão, o cavalheiro sempre conduziu sua dama, restando a ela um papel passivo de segui-lo em sua movimentação, deslocamento e musicalidade".

\section{Considerações finais}

Os espaços de Danças de Salão, apesar de continuarem como locais de manutenção de discursos e atitudes machistas e heteronormativas, têm sofrido a ação das mudanças nas perspectivas dos estudos de gênero e do feminismo, havendo sinais de alterações para proposições de discussão dessas perspectivas por profissionais e praticantes, pois isso se apresenta hoje como uma urgência social.

Assim, podemos considerar que, no momento atual, ainda não avançamos passos significativos no cotidiano da prática profissional das Danças de Salão. Apesar do crescente número de pesquisas acadêmicas que questionam as relações estabelecidas nos espaços de Danças de Salão, profissio-

FREIRE, Francisca Jocélia de Oliveira; ACCIOLY, Cecília Bastos da Costa. Em questões de gênero e normatividade, quantos passos avançamos no salão?.

PÓS:Revista do Programa de Pós-graduação em Artes da EBA/UFMG. v. 11, n. 22, mai-ago. 2021 Disponível em < $\underline{\text { https://doi.org/10.35699/2237-5864.2021.25827 }>~}$ 
nais que estão à frente de aulas, eventos e atividades oferecidas ao grande público, em sua maioria, não dedicam atenção a questões críticas relacionadas à sociedade, sendo a sua atuação determinante para reprodução do status quo.

É possível compreender, ainda, a partir da análise desses questionários, ser necessário tratar de tais questões a partir de uma ótica interseccional, categoria teórica que possibilita uma análise múltipla de sistemas de opressão, dentre eles a construção do poder estabelecido socialmente no sistema cis-hétero-patriarcal, o mesmo que serve como modelo para as determinações estabelecidas no formato tradicional das Danças de Salão.

FREIRE, Francisca Jocélia de Oliveira; ACCIOLY, Cecília Bastos da Costa. Em questóes de gênero e normatividade, quantos passos avançamos no salão?.

PÓS:Revista do Programa de Pós-graduação em Artes da EBA/UFMG. v. 11, n. 22, mai-ago. 2021 Disponível em < $\underline{\text { https://doi.org/10.35699/2237-5864.2021.25827 }>~}$ 


\section{REFERÊNCIAS}

AKOTIRENE, Carla. Interseccionalidade. São Paulo: Sueli Carneiro; Pólen, 2019.

D'ÁVILA, Cristina; MADEIRA, Ana Verena (org.). Ateliê Didático: uma abordagem criativa na formação continuada de docentes universitários. Salvador: EDUFBA, 2018. Disponível em: <http://repositorio.ufba.br/ri/handle/ri/29316>. Acesso em: 10 out. 2020.

DRUMONT, Mary Pimentel. Elementos para uma análise do machismo. São Paulo: Perspectivas, 1980.

FEITOZA, Jonas Karlos de Souza. Danças de Salão: os corpos iguais em seus propósitos e diferentes em suas experiências. 2011. 85 f. Dissertação (Mestrado em Dança) - Escola de Dança, Universidade Federal da Bahia, Salvador, 2011. Disponível em: <https://repositorio.ufba.br/ri/handle/ri/8141>. Acesso em: 10 out. 2020.

LOURO, Guacira Lopes. Gênero, sexualidade e educação: uma perspectiva pós-estruturalista. Petrópolis: Vozes, 1997.

NUNES, Bruno; FROEHLICH, Marcia. Um novo olhar sobre a condução na dança de salão: questões de gênero e relações de poder. Revista educação, artes e inclusão, v. 14, n. 2, p. 91-116, abr.-jun. 2018. Disponível em: <https://periodicos.udesc.br/index.php/arteinclusao/article/view/10172>. Acesso em: 10 out. 2020.

NUNES, Joaquim Moreira; INFANTE, Maria. Pesquisa-ação: uma metodologia de consultoria. Rio de Janeiro: Editora FIOCRUZ, 1996. Disponível em: <http://books.scielo.org/id/dydn3/10>. Acesso em: 10 out. 2020.

PAZETTO, Debora; SAMWAYS, Samuel. Para além de damas e cavalheiros: uma abordagem Queer das normas de gênero na dança de salão. Revista educação, artes e inclusão, v. 14, n. 3, p. 157179, jul.-set. 2018. Disponível em:

<https://periodicos.udesc.br/index.php/arteinclusao/article/view/11736>. Acesso em: 10 out. 2020.

POLEZI, Carolina; VASCONCELOS, Paola. Contracondutas no ensino e prática da Dança de Salão: a dança de salão queer e a condução compartilhada. Artículo Presencia. Miradas desde y hacia la Educación, Montevideo, n. 2, 2017. Disponível em:

$<$ https://www.stellamaris.edu.uy/revistapresencia/2017/12/06/contracondutas-no-ensino-epratica-da-danca-de-salao-a-danca-de-salao-queer-e-a-conducao-compartilhada/>. Acesso em: 10 out. 2020.

SAFFIOTI, Heleieth. Gênero, Patriarcado, Violência. São Paulo: Expressão Popular, 2015.

SILVEIRA, Paola de Vasconcelos. Pela urgência do fim da boa dama - os papéis de gênero na dança de salão. Anais ABRACE, v. 19, n. 1, 2018. Disponível em:

$<$ https://www.publionline.iar.unicamp.br/index.php/abrace/article/view/3999/4099>. Acesso em: 10 out. 2020.

FREIRE, Francisca Jocélia de Oliveira; ACCIOLY, Cecília Bastos da Costa. Em questões de gênero e normatividade, quantos passos avançamos no salão?.

PÓS:Revista do Programa de Pós-graduação em Artes da EBA/UFMG. v. 11, n. 22, mai-ago. 2021 Disponível em < $\underline{\text { https://doi.org/10.35699/2237-5864.2021.25827 }>~}$ 